\title{
Collusion with asymmetric retailers: Evidence from a gasoline price-fixing case Online appendix
}

\author{
By Robert Clark and Jean-François Houde*
}

This online appendix contains (I) a description of the Competition Bureau documents, (II) a numerical model of tacit collusion, and (III) an additional table of results.

\section{Competition Bureau documents}

For the purpose of this paper, we base our understanding of the facts with respect to the alleged Quebec retail-gasoline cartel case mostly on documents prepared by the Competition Bureau. We were given a copy of the 52-page affidavit of Mr. Pierre-Yves Guay of the Competition Bureau dated May 16, 2006 in file no 500-26-039962-067 of the Superior Court of Quebec, district of Montreal. From the Court, we received copies of the three annexes attached to the affidavit of Mr. Guay. Annex A is a 143-page document which contains mostly reported wiretap telephone conversations with respect to the region of Victoriaville; Annex $\mathrm{B}$ is a 45-page document which contains mostly reported wiretap telephone conversations with respect to the region of Thetford Mines; Annex C is a 121-page document which contains mostly reported wiretap telephone conversation with respect to the regions of Sherbrooke and Magog. We will refer to the affidavit of Mr. Guay and its three annexes as the "Competition Bureau documents." We also found information on the actions taken by the Competition Bureau on its website : http://www.competitionbureau.gc.ca.

The wire taps took place from March to June 2005 in Victoriaville and ThetfordMines, and from March to June 2005 and December 2005 to April 2006 in Sherbrooke/Magog. For each price adjustment attempt that is documented, the phone calls are listed along with an extract or a summary of the individual conversations (including information about who made the call, who received the call, and the time of the call). For example, pages 27 and 41 of Annex A represent a typical entry for a price adjustment attempt. The annex makes reference to a 4 cent per liter price increase attempt on April 6th 2005 in Victoriaville. The Competition Bureau explains that the increase was initiated by two players and that twenty-three gas stations were involved. The annex lists these stations, and

\footnotetext{
* Correspondence to Robert Clark: HEC Montréal, CIRANO and CIRPÉE, Montréal, Québec; Phone: (514) 340-7034; Email: robert.clark@hec.ca, and Jean-François Houde: Wharton School, University of Pennsylvania and NBER, 3620 Locust Walk, Philadelphia, PA 19104, USA. E-mail: houde@wharton.upenn.edu.
} 
then summarizes eighty-eight telephone conversations which took place between 6:44 am and 3:42 pm. The summaries explain that the price increase was to take place at 9:15 am. Finally, in the annex the Bureau concludes that according to observations in the field, the agreement had been executed.

Table 1a describes the price increases that occurred in Thetford Mines and Victoriaville during the period. The table presents information from the court documents on the initial price, the target price, and the price following the adjustment, along with information on whether the adjustment was successful (in the sense that all cartel members had adjusted their price by the end of the attempt). In Thetford Mines there were five price increase attempts during this period, all of which were successful. In Victoriaville there were six successful price increase attempts. In Sherbrooke/Magog, there were seventeen price increase attempts during the two wire tap periods, of which twelve were at least partially successful (we denote partial success by $\mathrm{P}$ ). Table $1 \mathrm{~b}$ describes these price increases.

Table 2 describes the periods between coordinated price increases in Victoriaville and Thetford Mines. In between the large price increases that occur there are typically a series of small price decreases ( 1 to 2 cents) along with periods of stability (of between 5 and 9 days). In Victoriaville there are three such periods during the wire-tap, while in Thetford Mines there are two. There are no entries describing coordinated price decreases in the Competition Bureau documents (although in the entries for two price increases, the price decreases that preceded them are discussed). 
Table 1-: Price increases

(a) Thetford Mines and Victoriaville

\begin{tabular}{l|ccccc}
\hline Date & Before & Target & After & Calls & Success \\
\hline & \multicolumn{5}{c}{ Thetford Mines } \\
8-Mar & 86.4 & 94.4 & 94.4 & 30 & yes \\
6-Apr & 94.4 & 98.4 & 98.4 & 52 & yes \\
26-Apr & 93.4 & 99.4 & 99.4 & 24 & yes \\
3-Jun & 92.4 & 97.4 & 97.4 & 41 & yes \\
22-Jun & 97.4 & 99.4 & 99.4 & 32 & yes \\
& \multicolumn{5}{c}{ Victoriaville } \\
4-Mar & 83.9 & 85.9 & 85.9 & 7 & no \\
8-Mar & 85.9 & 94.9 & 86.9 & 25 & no \\
15-Mar & 86.7 & 89.9 & 89.9 & 28 & yes \\
30-Mar & 89.9 & 94.9 & 94.9 & 89 & yes \\
6-Apr & 94.9 & 98.9 & 98.9 & 88 & yes \\
26-Apr & 94.9 & 99.9 & 99.9 & 70 & yes \\
3-Jun & 89.9 & 97.9 & 96.9 & 84 & yes \\
22-Jun & 94.9 & 99.9 & 94.9 & 69 & no \\
23-Jun & 94.9 & 99.9 & 99.9 & 85 & yes \\
\hline
\end{tabular}

(b) Sherbrooke and Magog

\begin{tabular}{l|ccccc}
\hline Date & Before & Target & After & Calls & Success \\
\hline 21-Apr & 93.4 & & & & \\
27-May & 91.4 & 95.4 & 91.4 & 87 & yes \\
1-Jun & 91.4 & 96.9 & 91.4 & 57 & no \\
3-Jun & 91.4 & 97.4 & 91.4 & 8 & no \\
7-Jun & 91.4 & 98.4 & 98.4 & 30 & yes \\
15-Jun & 91.4 & 99.4 & 97.4 & 56 & yes \\
21-Jun & 97.4 & 99.9 & 97.4 & 12 & no \\
27-Jun & 97.4 & 102.4 & 99.4 & 33 & yes \\
16-Aug & 106.4 & & 110.4 & $\mathrm{n} / \mathrm{a}$ & $\mathrm{P}$ \\
6-Dec & 92.4 & & 96.4 & $\mathrm{n} / \mathrm{a}$ & $\mathrm{P}$ \\
4-Jan & 98.4 & 104.4 & 104.4 & 23 & yes \\
22-Jan & 92 & 96.9 & 96.4 & 42 & yes \\
10-Mar & 96.4 & 99.4 & 99.4 & 99 & yes \\
15-Mar & 99.4 & 107.4 & 107.4 & 92 & yes \\
31-Mar & & 110.4 & 110.4 & 74 & yes \\
12-Apr & 108.4 & 113.4 & 113.3 & 73 & yes \\
18-Apr & & 115.4 & 115.4 & 32 & n/a \\
\hline
\end{tabular}


Table 2-: Price decrease periods - Victoriaville and Thetford Mines

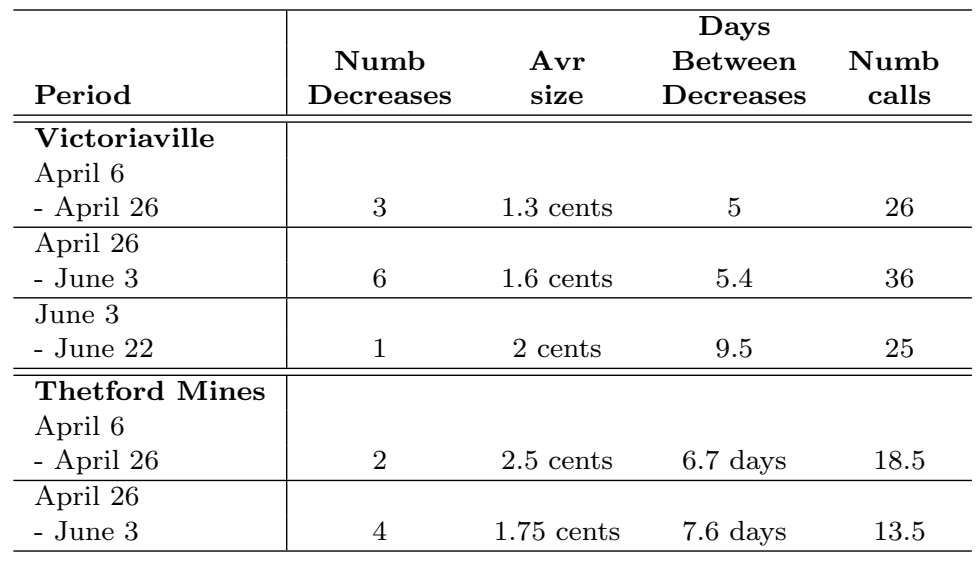




\section{A model of tacit collusion with asymmetric retailers}

Using the simple Bertrand model described in Section III of the paper we study the role of temporary price differences. We focus on the symmetric collusive market share case $\left(s_{H}=s_{L}\right)$. In Section II.A we consider the effect of an intertemporal transfer scheme based on temporary price differences. In Section II.B we study the effect of the price floor in incentives.

\section{A. Temporary price differences as transfers}

In Table 3a we provide a numerical example illustrating an inter-temporal transfer scheme based on temporary price differences in a market with heterogeneous costs: Firms agree on setting a common price $\bar{p}$, and on allowing the low-cost firm to hold a sale at price $p^{d}<\bar{p}$ every $T+1$ periods. This strategy implies that the high-cost firm agrees to give-up one period of sales every cycle. When negotiating the agreement, firms face a tradeoff between colluding on a higher price, and increasing the frequency of sales. We use a Nash bargaining solution in which firms' threat points are determined by the value of deviating to solve this tradeoff.

The middle columns illustrate the changes in the collusive arrangements as the cost asymmetry increases. With small asymmetries (i.e. $c=0.1$ ), collusion is feasible without transfers. However, since firms disagree on the optimal collusive price, the high-cost firm is willing to transfer market shares to its opponent every 3 periods in order to collude on a higher price, relative to the collusive price without transfers. With larger asymmetries, the agreements involve both higher prices and shorter cycles. In the last two rows, the asymmetries are too large to sustain collusion even with transfers.

\section{B. The role of the price floor and competition}

A second constraint on collusion that becomes relevant in our context is the presence of the price-floor regulation that exists in the Province. In general, price floor regulations can have two competing effects when binding in the punishment phase: (i) to raise the punishment revenues, and (ii) to reduce the market shares of the most efficient stores. The overall effect on collusion is thus ambiguous, and depends on the source of heterogeneity between firms.

When firms have symmetric costs, the market share effect is not present, and a binding floor simply reduces the severity of the punishments. Similarly, high-cost firms strictly benefit from a price floor policy, since their value of deviating is increased.

When cost asymmetries are present, a binding price floor can reduce the value of deviating for the low-cost firm. For instance, consider the previous example in which a price floor, like in the Québec case, is set to protect the least efficient 
Table 3-: Equilibrium collusive agreements for different levels of cost asymmetries and market structure

(a) Duopoly example

\begin{tabular}{cc|ccc|ccc} 
Asymmetry & Monopoly & \multicolumn{3}{|c|}{ No Price floor } & \multicolumn{3}{|c}{ Price floor = c } \\
Largest $c$ & price (max) & $\bar{p}$ & $T$ & Enforceable & $\bar{p}$ & $T$ & Enforceable \\
\hline 0.1 & 0.55 & 0.526 & 2 & 1 & 0.527 & 4 & 1 \\
0.15 & 0.575 & 0.542 & 1 & 0 & 0.542 & 3 & 1 \\
0.2 & 0.6 & 0.538 & 1 & 0 & 0.56 & 2 & 1 \\
0.3 & 0.65 &. NaN &. NaN & 0 & 0.607 & 1 & 0 \\
0.4 & 0.7 &. NaN & .NaN & 0 & 0.646 & 1 & 0
\end{tabular}

(b) Three firms example

\begin{tabular}{cc|ccc|ccc} 
Asymmetry & Monopoly & \multicolumn{3}{|c|}{ Inefficient competitor } & \multicolumn{3}{c}{ Efficient competitor $\left(c_{m}=0.1\right)$} \\
Largest $c$ & price (max) & $\bar{p}$ & $T$ & Enforceable & $\bar{p}$ & $T$ & Enforceable \\
\hline 0.2 & 0.6 & 0.569 & 2 & 1 & 0.569 & 2 & 1 \\
0.25 & 0.625 & 0.601 & 1 & 0 & 0.586 & 2 & 0 \\
0.3 & 0.65 & 0.622 & 1 & 0 & 0.592 & 3 & 0 \\
0.35 & 0.675 & 0.644 & 1 & 0 & 0.582 & 6 & 0 \\
0.4 & 0.7 & 0.668 & 1 & 0 & 0.563 & 12 & 0
\end{tabular}

Each $\bar{p}$ and $T$ entries are the outcomes of the Nash bargaining game between the lowest and highest cost firm, subject to the agreement being enforceable by all firms. The maximum monopoly price is the monopoly price of the highest cost firm. Enforceable is a dummy variable indicating whether or not collusion is feasible at the lowest monopoly price without transfers. The discount factor is set to 0.98 and the lowest marginal cost is equal to 0 . Entries with .NaN are not enforceable for any cycle length or prices. In the three-firm case, we assume that the high-cost and low-cost firms negotiate the agreement among themselves, subject to an enforceability constraint that must be satisfied for all three firms. In the Inefficient competitor example, the marginal cost of the middle firm is equal to $c$. In the Efficient competitor example, the marginal cost of the middle firm is constant and equal to 0.1. All examples assume a linear demand function: $D(p)=1-\min \left\{p_{L}, p_{H}\right\}$.

store: $p_{f}=c+\mu$. In this case, for small values of $\mu$, the value of deviating for type $L$ is nearly cut in half:

$$
\lim _{\mu \rightarrow 0^{+}} V_{L}^{d}(\mu)=D\left(p_{L}^{d}\right) p_{L}^{d}+\delta \frac{D(c) c}{2(1-\delta)}>D\left(p_{L}^{d}\right) p_{L}^{d}+\delta \frac{D(c) c}{(1-\delta)}=V_{L}^{d}(\mu=0) .
$$

Therefore, for a moderately small price floor that is larger than or equal to the high-cost marginal cost, collusion is easier to sustain since the floor eliminates cost asymmetries in the punishment phase. This is not the case when asymmetries are solely in terms of market share, in which case a price floor strictly reduces the likelihood of collusion.

The last three columns of Table 3a illustrate the impact of the price floor on the collusive agreement with cost asymmetries. As the last column shows, a market with a floor can sustain collusion without transfer for a larger range of asymmetries (i.e. up to 0.3 in the example). The relative bargaining position of the two firms also changes because $V_{L}^{d}$ is lowered. In the first three cases this means either 
a higher collusive price, and/or a longer cycle length (i.e. smaller transfers). For large asymmetries, the length of the cycles can implement equilibria that would not be feasible with a constant price, or without the price floor regulation. In the last two, firms agree on high prices and frequent periods of sales (every two periods).

The next two examples in Table $3 \mathrm{~b}$ consider a similar situation, but add a third competitor with marginal cost $c_{M} \leq c$. Intuitively, when the number of firms making transfers increases, the cost of allowing frequent sales can be large enough to violate the incentive constraint of the intermediate competitor(s). For competition to constrain the frequency of transfers in this way, the third competitor must be relatively more efficient than the high-cost firm.

In the middle columns, we add a competitor that has the same cost structure as the high-cost firm. In this case, the participation constraint of this middle firm is irrelevant, and adding the third firm tends to decrease the value of deviation and facilitate collusion. Next, we consider an example in which the middle competitor is more efficient (i.e. $c_{H}>c_{M}=0.1$ ). In this case, adding the third competitor changes the nature of the agreement if its participation constraint binds. In our example, this occurs for intermediate and large cost asymmetries. For $c=0.25$ the presence of the third firm constrains the frequency of transfers to be larger than 2, which leads to a lower equilibrium price. When we increase the cost asymmetries, the length of the cycles is further increased, and the equilibrium price is actually decreasing in $c$. 


\section{Additional results appendix}

Table 4-: Logit demand parameter estimates (standard-errors in parenthesis)

\begin{tabular}{lccc}
\hline VARIABLES & Victoriaville & Shrerbrooke & Thetford Mines \\
\hline Price coefficient $(\alpha)$ & -0.409 & -0.409 & -0.409 \\
& $(0.068)$ & & \\
Number of pumps & 0.081 & 0.00804 & 0.0589 \\
& $(0.017)$ & $(0.004)$ & $(0.013)$ \\
Full service & 0.178 & -0.434 & 0.0204 \\
& $(0.084)$ & $(0.076)$ & $(0.120)$ \\
Major brand & 0.186 & 0.764 & -0.217 \\
& $(0.093)$ & $(0.070)$ & $(0.181)$ \\
24 Hours & -0.218 & -0.0257 & 0.677 \\
& $(0.093)$ & $(0.056)$ & $(0.221)$ \\
Conv. Store - Small & 0.207 & -0.249 & \\
& $(0.146)$ & $(0.060)$ & \\
Conv. Store - Medium & -0.0423 & -0.246 & -0.478 \\
& $(0.134)$ & $(0.087)$ & $(0.121)$ \\
Conv. Store - Large & 0.169 & -0.556 & -0.746 \\
& $(0.144)$ & $(0.093)$ & $(0.111)$ \\
Islands=1 & & & -0.249 \\
& & & $(0.083)$ \\
Islands=2 & 0.331 & 0.106 & \\
Islands=3 & $(0.093)$ & $(0.055)$ & \\
Islands $\geq 4$ & 0.408 & 0.507 & \\
& $(0.193)$ & $(0.072)$ & \\
Nb. Observations & & 0.341 & \\
RSS N & 463 & $(0.063)$ & \\
& 0.213 & 1340 & \\
& & 0.212 & 0.095 \\
\hline & & &
\end{tabular}

Note: $\alpha$ in columns $(2)$ and $(3)$ is restricted to -0.409 . 